\title{
Influence of customer attitude on uptake of life insurance among teachers in Uasin Gishu County - Kenya
}

\author{
Nelson Kimeli Kemboi Yego ${ }^{1,}$, , Kennedy Kipkosgei Salbei ${ }^{2}$, Evans Mbuthi Kilonzo ${ }^{1}$ \\ ${ }^{1}$ Dept. of Statistics and Computer Science, Moi University (MU), Eldoret, Kenya \\ ${ }^{2}$ Mt. Kenya University (MKU), Department of Finance, Eldoret, Kenya
}

Email address:

nelsonyego@gmail.com (N. K. K. Yego), salwaters13@gmail.com (K. K. Salbei)

To cite this article:

Nelson Kimeli Kemboi Yego, Kennedy Kipkosgei Salbei, Evans Mbuthi Kilonzo. Influence of Customer Attitude on Uptake of Life Insurance among Teachers in Uasin Gishu County - Kenya. American Journal of Applied Mathematics. Vol. 2, No. 5, 2014, pp. $191-196$. doi: 10.11648/j.ajam.20140205.17

\begin{abstract}
Despite its importance in business, economic growth, and particularly in financial services sector, life insurance in Kenya has experienced low uptake. This research sought to find out the customer attitude influence on the uptake of life insurance among teachers in Uasin Gishu County, Kenya. The research focused on customer attitude as a factor. A survey of the teachers in the Uasin Gishu County, Kenya was carried out. 302 teachers in Wareng Sub-county were sampled. Content Validity Index (CVI) was used to measure the validity of the research instruments. Moreover, pilot of 35 questionnaires was used to enhance the instrument's reliability. It was found out that there exists some relationship between customer attitude and the level of uptake of life insurance among teachers in Uasin Gishu County since the correlation coefficient $r$ of 0.433 was established and a $\mathrm{p}$ value of 0.000 . Hence the $\mathrm{p}$ value is less than $\alpha=0.01$, which is the set significant level. Moreover, a regression of the standardized beta values, of 0.0 .713 was found. This meant the customer attitude influences the level of uptake of life insurance by teachers. The findings pointed that great effort should put by stakeholders to increase perception of life insurance and hence enhance customer attitude.
\end{abstract}

Keywords: Life Insurance, Customer Attitude, and Uptake

\section{Introduction}

According to (Brainard, 2008), the importance of insurance in business, economic growth, and particularly in financial services sector cannot be overemphasized. The indemnification and risk pooling properties of insurance facilitate commercial transactions and the provision of credit by mitigating losses as well as the measurement and management of non-diversifiable risk more generally.

Most fundamentally, the availability of insurance enables risk averse individuals and entrepreneurs to undertake higher risk, higher return activities than they would do in the absence of insurance, promoting higher productivity and growth. It is imperative therefore, that the deepening of insurance markets makes a positive contribution to economic growth. Insurance and banking system deepening play complementary roles in the growth process.

The Government of Kenya developed the Kenya vision 2030 to guide the country's development strategy. The Vision 2030 seeks to transform Kenya into a globally competitive and prosperous nation by 2030. (Government of the Republic of Kenya, 2007). Moreover, one of the parts of the Economic pillar is to increase the contribution of the insurance to the GDP. (Insurance Regulatory Authority, 2012) However, the IRA cites low uptake of life Insurance as one the challenges facing the realization of the vision.

According to (Insurance Regulatory Authority, 2013), the number of insurance companies registered and licensed has increased to 51.12 of these are pure life, 13 are composite, while the rest 26 are general insurance providers.

(Smith, Chamberlain, Smit, Ncube, \& Chelwa, December 2010), gave that the Insurance Regulatory Authority (IRA), in Kenya, has been on doing its best to better the situation by placing increasing emphasis on the professionalization of the Kenyan insurance industry. This includes significantly increased capital requirements, which insurance companies have had to comply with from June 2010.

The Authority has further spearheaded the amendment of the Insurance Act. In addition to regulating and supervising the insurance industry, the amendments added the mandate of 
market development to the Insurance Regulatory Authority's list of tasks. The Act phrases the development mandate as to promote the development of the sector. This development mandate has shaped the way that the IRA has managed the development of the insurance industry and, in particular, how it has navigated the short-comings in the existing insurance legislation (Insurance Regulatory Authority, 2012)

The IRA has shown its support for the development of a micro insurance market in various ways, including exempting insurance companies and non-traditional intermediaries from the different parts of the Insurance Act to allow for the implementation of innovative micro insurance models. These exemptions have generally been provided on an ad hoc and case-by-case basis, with the exemption not being generalized to the market

Despite the efforts put by various stakeholders, (Okoth, 2013), still pointed that nine insurance companies, in Kenya, found them posting huge losses in 2012. According to him this was as result of a combination of fraudulent claims and low uptake of products took a toll on their earnings. He said that only seven per cent of the Kenyan population has one form of insurance or another, leaving a big market that insurance is yet to penetrate. It is against this background that this study sought to find influence that attitude has on the uptake of life insurance policies by teachers in Uasin Gishu County.

\subsection{Statement of the Problem}

According to (Association of Kenya Insurers , 2010), life assurance provides cover to an individual policy holder against ill health, disability, premature death, natural calamities and financial stability in old age.

According to Association of Kenya Insurers, (2010), uptake of life insurance in Kenya is low. When compared to Malaysia which has an estimated $41 \%$ of the population covered by some form of life insurance Kenya is comparatively with less than $1 \%$ of the population insured. (Association of Kenya Insurers , 2010)

(Association of Kenya Insurers , 2010), in the AKI Insurance Annual Report points that the life insurance industry in Kenya has been in its stumpy with the uptake of life insurance at $0.94 \%$ of the GDP in 2009 and at $1.05 \%$ of the GDP in 2010. This is considered to be very low compared to South Africa which had a uptake of $7.58 \%$ of the GDP in 2009 and $12 \%$ of the GDP in 2010 while Namibia's was $5 \%$ of the GDP in 2010.

Life insurance is beneficial in that the financial interests of one's family remain protected from circumstances such as loss of income due to critical illness or death of the policyholder and insurance products also have a strong inbuilt wealth creation proposition. It is therefore necessary to find out influence of customer attitude on uptake of life insurance in Kenya.

\subsection{General Objective}

The general objective of this study is to find out the influence that customer attitude has on the uptake of life insurance among teachers in Uasin Gishu County.

\subsection{Specific Objectives}

The study was guided by the following research objectives:

a) To determine the magnitude customer attitude affecting the uptake of life insurance among teachers in Uasin Gishu county

b) To assess the level of uptake life insurance among teachers in Uasin Gishu County.

c) To establish the influence of the customer attitude of the uptake of life insurance among teachers in Uasin Gishu County.

\subsection{Hypothesis of the Study}

$\mathrm{H}_{0}$-There is no relationship between customer attitude and uptake of life insurance.

$\mathrm{H}_{1}$-There is a relationship customer attitude and uptake of life insurance.

\subsection{Significance of the Study}

Life insurance companies would find this study useful in its suggestions about how customer attitude contributes to the industry having low life insurance uptake among the teachers It will be of great reference to the life insurance industry in drawing strategies and programs aimed at increasing the uptake of insurance policies and hence life insurance uptake especially among the teachers and elites in general. It will help policy holders and potential policy holders to know exactly what to expect in their dealings with life insurance companies in particular and the insurance industry in general. The study will also be of importance to the Government of Kenya, through the Commissioner of Insurance in coming up with appropriate legislation that will ensure there is congruence between policy holders, potential policy holders and the insurance companies. The Association of Kenya Insurers (AKI) will use the findings on customer attitude influencing the uptake of life insurance in Kenya to strengthen and evaluate its role in the industry. The findings of this study are expected to not only help in filling the void that exists in Kenya as regards research and publications on life insurance, but also to stimulate discussion in the academic field and provide a fertile ground up on which further research could be based.

\subsection{Scope of the Study}

This study focuses on financial service sector of the economy, specifically insurance sub sector and more narrowly life insurance part of it. The study covers all life insurance among teachers teaching within Uasin Gishu County, Kenya. The main areas of focus are on how sociodemographic characteristics, pricing, banc assurance, awareness and the attitude that influence the uptake of the life insurance policies among teachers in the county.

The geographical scope includes Uasin Gishu County. The area is chosen because it is one of the largest, cosmopolitan 
counties in the country, Kenya. For that reason therefore, it was taken as being representative of other counties in the country. The study was carried out between May and June of the year 2014 .

\section{Research Design}

This study used descriptive survey design. (Knupfer \& McLellan, 2001), postulate that descriptive research does not fit neatly into the definition of either quantitative or qualitative research methodologies, but instead it can utilize elements of both, often within the same study.

Knupfer \& McLellan, (2001), further assert that the term descriptive research refers to the type of research question, design, and data analysis that will be applied to a given topic. They acknowledge that a descriptive survey is a powerful form of qualitative analysis that involves a careful and complete observation of a number of units to deduce. They put that it also allows for the description of a given phenomenon in a systematic and systematic manner to allow drawing of conclusions and generalization of the general population.

This design was also considered appropriate since data collected from since the study was only concerned with getting the situation as it is without changing the circumstances in any way. The design allowed the researcher to study the relationships of variables with minimal bias and maximal reliability.

\subsection{Population}

According to (Katamba \& Nsubuga, 2013), population can be defined as including all people or items with the characteristic the researcher wishes to understand. The target population of the study consisted of all life insurable teachers in Uasin Gishu County, Kenya. Teachers in this study refer to both secondary and primary school teachers in all the schools as recognized by the ministry of education office in Eldoret. These are clients and potential clients of the all insurers among teachers in Uasin Gishu County, Kenya. The assumption of this paper was that all the teachers, employed in the county, are insurable hence it was taken that the population for this study includes all the teachers in Uasin Gishu County (both those teaching in primary school and those teaching in secondary school).

Table 1. Number of Teachers as per Sub-county

\begin{tabular}{ll}
\hline Sub-county & Number of teachers \\
\hline Eldoret municipality & 924 \\
Eldoret west & 1813 \\
Eldoret east & 1430 \\
Wareng & 1404 \\
Total & 5571 \\
\hline
\end{tabular}

According to the ministry of education the population of teachers in Uasin Gishu County is 5571 teachers. The teacher distribution according to the various Sub-counties within the county was such that Eldoret municipality had 924 teachers, Eldoret west had 1813, Eldoret east had 1430, while Wareng had 1404. (Teachers Service Commission, 2013)

Moreover, the case study concentrated in Wareng Subcounty which has a population of 1404 teachers. Wareng Sub-county was chosen because it has the highest number of centers, moreover, it captures not only the urban Eldoret but also it has a big part of the rural hence best representative of the county.

\subsection{Sample Size}

The researcher determined the sample size according to Morgan formula (1979) whereby the target population will be determine at a margin error of 0.05 at $95.0 \%$ confidence give a sample size of 302 .

Size calculation: Morgan formula

$n$ - Sample population

$N$-Total population

$$
n=\frac{N}{1+N(e)^{2}}=\frac{1404}{1+1404(0.0025)}=302
$$

$e$ - Desired margin of error $(0.05)^{2}$

\subsection{Sampling Procedure}

Table 2. Sampling Frame

\begin{tabular}{|c|c|c|c|c|c|}
\hline Zone & Primary Teachers & Sample & Secondary Teachers & Sample & Total Teachers \\
\hline Kapseret & 291 & 61 & 153 & 35 & 444 \\
\hline Kesses & 228 & 48 & 54 & 12 & 282 \\
\hline Tulwet & 153 & 32 & 30 & 7 & 183 \\
\hline Cheptiret & 191 & 40 & 74 & 17 & 265 \\
\hline Timboroa & 186 & 39 & 44 & 10 & 230 \\
\hline Total & 1049 & & 355 & & 1404 \\
\hline Sample size & 221 & & 81 & & 302 \\
\hline
\end{tabular}

This study adopted stratified random sampling. It involved dividing the population into homogeneous subgroups and then taking a simple random sample in each subgroup. The major reason why stratified sampling is because it assured that the study could be able to represent not only the overall population, but also key subgroups of the population. 
According to (Trochim \& Donnelly, 2006), this will only be true if the strata or groups are homogeneous. If they are, we expect that the variability within-groups are lower than the variability for the population as a whole. In this study the strata is the various zones in which the Sub-county is divided into.

\subsection{Research Instruments}

The study made use of questionnaires and interviews schedules for data collection. Questionnaire was used for collecting primary data from the key respondents. Moreover, secondary data was sought for clarification.

In giving use of semi structured questionnaire as a tool for collecting data (Neville, July 2007), says that the researcher will have a list of themes and areas to be covered and there may be some standardized questions. He further puts that the researcher may omit or add to some of these questions or areas, depending on the situation and the flow of the conversation.

This data collection instruments contained questions that allowed for unambiguous responses and were easier to administer, the researcher ensured questionnaire was consistent with the data analysis method used.

\subsection{Reliability and Validity}

Table 3. Questions on Customer Attitude

\begin{tabular}{llll}
\hline Question & Mean & $\begin{array}{l}\text { Std. } \\
\text { Deviation }\end{array}$ & Interpretation \\
\hline $\begin{array}{l}\text { I am always ready to refer } \\
\text { my friends to buy the life } \\
\text { insurance products }\end{array}$ & 3.12 & 0.76 & Moderate \\
$\begin{array}{l}\text { Compensation by } \\
\text { insurance companies is } \\
\text { complicated }\end{array}$ & 3.17 & 0.80 & Moderate \\
$\begin{array}{l}\text { The life insurance } \\
\text { policies are makes my life } \\
\text { or that of others better. }\end{array}$ & 3.29 & 0.77 & Moderate \\
Average & 3.20 & 0.78 & Moderate \\
\hline
\end{tabular}

(Saunders, Lewis, \& Thornhill, 2009), argues that a research is only valid when its findings become verifiable. In testing the validity of the research instrument the researcher first formulated the research questions according to the intended study objectives and questions. After which the researcher presented the formulated questions in the questionnaire to other research experts for verification on whether the questions can answer the intended research objective.

According to Thomas.C.Kinnear and James R Taylor (2000), validity of the research instrument was examined by calculating the content validity index with 0.6 being the minimal.

\subsection{Customer Attitude}

This research sought to find the notion that the clients have on life insurance products. To arrive at this three five point likert scale questions were employed to establish the attitude of the clients and potential clients. The first sought to find how ready the respondents were to refer friends to buy the life insurance products the mean score was 3.12 with a standard deviation of 0.76 . This was interpreted as moderate. The second sought to find out the attitude towards compensation by insurance companies by rating how complicated it was. The mean score was found to be 3.17 with a standard deviation of 0.80 . This was also interpreted as moderate. The final question asked the respondents to rate the extent that life insurance policies make their life or that of others better. The mean in this case was 3.29 with a standard deviation of 0.77 . This was also interpreted as moderate. The aggregate average score was 3.20 with a standard deviation of 0.78 which is rated average.

\subsection{Level of Uptake Life Insurance}

The second objective of the study was to assess the level of uptake life insurance among teachers in Uasin Gishu County. This was assessed primarily by use of the mean of a five point likert scale questions in the questionnaire. Table 4 provides a summary of the findings. The first question sought find out how regularly the respondents renew life insurance policy whenever it expires. The mean in this case was found to be 2.38 with a standard deviation of 0.99 which was interpreted as low. The second sought find out the extent to which respondents were always willing to take up a life insurance cover the mean was found to be 3.12 with a standard deviation of 0.89 which was interpreted as moderate. Last question sought to the extent to which respondents constantly pay life insurance premiums on time the mean was found to be 2.99 with a standard deviation of 0.84 which was interpreted as moderate.

Table 4. Level of Uptake of Life Insurance

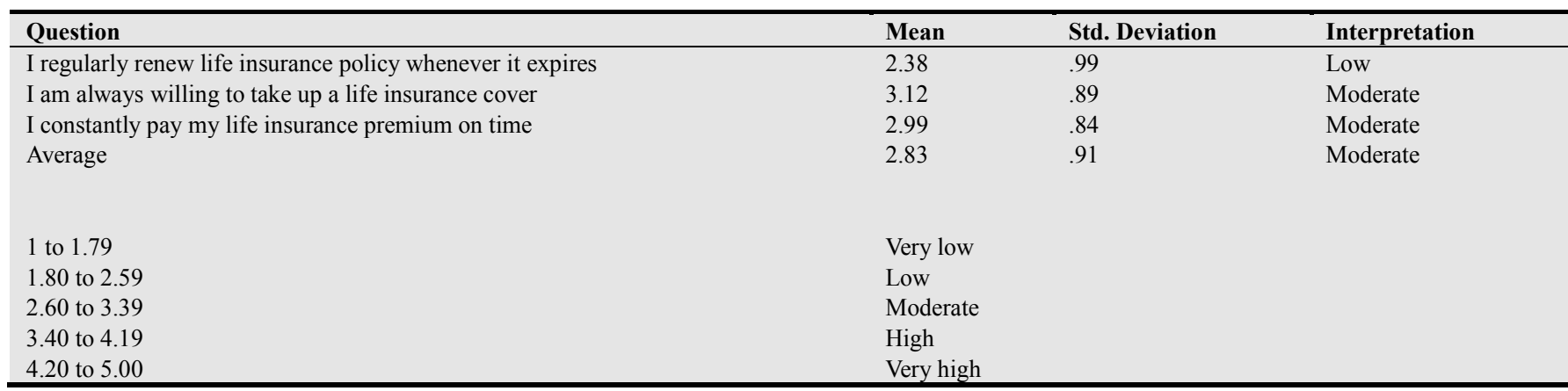


The aggregate mean was found to be 2.83 with a standard deviation of 0.91 which was interpreted as moderate. This implies the overall rate of the uptake of life insurance was moderate.

It can also be construed that the uptake of life insurance among teachers is generally higher than the general populace since according to (Association of Kenya Insurers , 2010) less than $1 \%$ of the population are insured as compared to the findings of this study which rated the uptake as being moderate. This can be attributed to the fact that the teachers were smore aware of the policies and by virtue of regular monthly income

Table 5. Influence of Customer Attitude on uptake of life insurance: Correlations

\begin{tabular}{llll}
\hline & & Customer Attitude & Uptake \\
\hline \multirow{2}{*}{ Customer } & Pearson Correlation & 1 & $.433^{* *}$ \\
Attitude & Sig. (2-tailed) & & .000 \\
& $\mathrm{~N}$ & 300 & 300 \\
& Pearson Correlation & $.433^{* *}$ & 1 \\
Uptake & Sig. (2-tailed) & .000 & 300 \\
& $\mathrm{~N}$ & 300 & \\
**. Correlation is significant at the 0.01 level (2-tailed). & Interpretation \\
Interval & & \multicolumn{2}{c}{ "very weak" } \\
$0.00-.19$ & & \multicolumn{2}{c}{ "weak" } \\
$0.20-.39-$ & & "moderate" \\
$0.40-.59$ & & "strong" \\
$0.60-.79$ & & "very strong" \\
$0.80-1.0$ & & \multicolumn{2}{c}{} \\
\hline
\end{tabular}

The finding also is in tandem with the findings of (FGI Research, 2014) who found that most people who indicated that they do carry life insurance, were mostly who had higher levels of education (a four-year college degree or higher).

\subsection{Influence of the Customer Attitude on Uptake of Life Insurance}

The third objective of the study was to establish the influence of the customer attitude of the uptake of life insurance among teachers in Uasin Gishu County. To arrive at that, correlation between the customer attitude and the uptake was calculated.

Moreover, regression of the standardized figures of customer attitude under consideration was used to establish the influence of the customer attitude on the uptake.

In the sample it was noted that the correlation was between 0 and 1 which implied that each of the two variables, considered in each case, tend to increase or decrease together. The respective micro interpretation is such that the closer is to 1 the stronger the monotonic relationship.

Correlation is an effect size and so we can verbally describe the strength of the correlation using the following guide for the absolute value of $r$. the interpretation was taken in such a way that for $\mathrm{r}$ values from 0.00 to.19, the relationship was to be interpreted as very weak $r$ values from 0.20 to .39 the relationship was to be interpreted as weak between 0.40 to .59 as moderate between $0.60-.79$ as "strong" and between 0.80 to 1.0 as very strong. (GraphPad Software Inc., 2014)

Table 5 above shows the relationship between customer attitude and level of uptake of life insurance in Uasin Gishu County, Kenya.

The correlation is coefficient customer attitude and level of uptake of life insurance at correlation coefficient $r$ value of .433 , which is interpreted as moderate. This implies that the customer attitude moderately influence the uptake of life insurance among teachers in Uasin Gishu County.

Moreover, according to the results of the Pearson correlation customer attitude and level of uptake of life insurance at correlation coefficient $r$ value of $.433^{* *}$ and $p$ value of .000 , this therefore mean that there are other factors affecting children education apart from customer attitude. In addition when correlation was manually calculated as illustrated, $(0.433 * 0.433=0.1875)$ this reveals that customer attitude influenced uptake of life insurance by $18.75 \%$ meaning that other factors were influencing uptake of life insurance by the remaining $81.25 \%$.

However, since the $\mathrm{p}$ value 0.000 was less than $\alpha 0.01$ $(0.000 \leq 0.01)$ the null hypothesis is rejected and accept the alternative. The researcher therefore concludes that there was a positive relationship between customer attitude and uptake of life insurance thus the null hypothesis is rejected that says that there is no relationship between customer attitude and uptake of life insurance.

Table 6. Regression

\begin{tabular}{|c|c|c|c|c|c|}
\hline \multicolumn{6}{|l|}{ Coefficients } \\
\hline & \multicolumn{2}{|c|}{ Unstandardized Coefficients } & \multirow{2}{*}{$\begin{array}{l}\text { Standardized Coefficients } \\
\text { Beta }\end{array}$} & \multirow[t]{2}{*}{$\mathbf{T}$} & \multirow[t]{2}{*}{ Sig. } \\
\hline & Beta & Std. Error & & & \\
\hline (Constant) & 3.405 & 0.513 & & 6.643 & 0 \\
\hline Customer Attitude & 0.713 & 0.051 & 0.76 & 13.932 & 0.000 \\
\hline
\end{tabular}

a. Dependent Variable: Level of Uptake of Life Insurance

Since the figures were obtained from a likert scale which is discrete, only standardized coefficient values were considered. This implies that the beta for the influence that the customer attitude under the study had on life insurance are the Standardized Coefficients as given in table 6.

Customer Attitude toward Life Insurance has a beta of 0.76 with a constant value of 13.932 and $p$ of 0.000 . The findings show that there is a strong linear relationship between customer attitude and uptake of life insurance. The better the perception customers have on life insurance, the higher the level of uptake. This is very much in tandem with the findings of (Mongin \& Claude d' Aspremont, 1998)who gave that individuals are risk-averse and therefore their attitude towards insurance is attitude toward paying to transfer risk. 


\section{Conclusions}

Basing on the hypothesis of the study, it was found out that there exists some relationship between the customer attitude and the level of uptake of life insurance among teachers in Uasin Gishu County. The null hypothesis was rejected and the alternative was taken meaning the customer attitude influence the level of uptake of life insurance by teachers. Moreover, it was found that this is not the only factor that influences the uptake of life insurance by teachers.

\section{References}

[1] Association of Kenya Insurance. (2012). AKI Annual Report. Nairobi: Association of Kenya Insurance.

[2] Association of Kenya Insurance. (2012, 11). Services. Retrieved 2012, from AKI: http://www.akinsure.or.ke/Services

[3] Association of Kenya Insurers . (2010). AKI Insurance Annual Report. Nairobi: AKI.

[4] Brainard, L. (2008, 01 14). What is the role of insurance in economic development? Zurich Government and Industry Affairs thought leadership series.(2), p. 16.

[5] FGI Research. (2014). 2013 Life Insurance Study Overview: Key Findings. Retrieved June 10, 2014, from FGI Research: http://info.fgiresearch.com/blog/bid/181516/2013-LifeInsurance-Study-Overview-Key-Findings

[6] Government of the Republic of Kenya. (2007). Kenya Vision 2030. Nairobi.

[7] GraphPad Software Inc. (2014). Interpreting results: Correlation. Retrieved 07 10, 2014, from Graphad Statistics Guide:

http://www.graphpad.com/guides/prism/6/statistics/index.htm? stat_interpreting_results_correlati.htm

[8] Insurance Regulatory Authority. (2012). Insurance Regulatory Authority Strategic Plan. Strategic Plan. Insurance Regulatory Authority.

[9] Insurance Regulatory Authority. (2013). Licencing and Regulation. Retrieved 10 10, 2013, from Insurance Regulatory Authority: http://www.ira.go.ke/
[10] Katamba, P., \& Nsubuga, T. (2013). Basic Research (1st ed.). Kampala, Uganda: Newgo Publishers.

[11] Kenya Information Guide. (2014). Uasin Gishu County. Retrieved June 8, 2014, from Key Facts About Kenya: http://www.kenya-information-guide.com/uasin-gishucounty.html

[12] Kenya National Bureau of Statistics. (2013). Population and Housing census 2009. Retrieved 04 08, 2014, from Kenya National Bureau of Statistics: http://www.knbs.or.ke/index.php?option=com phocadownloa $\mathrm{d} \&$ view=category\&id=109:population-and-housing-census2009\&Itemid $=599$

[13] Knupfer, N. N., \& McLellan, H. (2001). Handbook of Research for Educational Communications and Technology. (D. H. Jonassen, Ed.) New York: Macmillan.

[14] Mongin, P., \& Claude d' Aspremont. (1998). Utility Theory and Ethics. In P. H. Salvador Barbera (Ed.), Handbook of Utility Theory (Vol. 1, pp. 400-407). Boston: Kluwer Academic Publishers.

[15] Neville, C. (July 2007). Introduction to Research and Research Methods. Bradford: University of Bradford, School of Management.

[16] Okoth, J. (2013, 08 27). Nine insurance firms swim in losses on back of under-cutting. Daily Standard.

[17] Psucd8. (2011, 11 20). What is validity and why is it important in research? Retrieved 12 2012, 20, from Psucd8 Just another WordPress.com site: http://psucd8.wordpress.com/2011/11/20/why-is-validityimportant-in-research/

[18] Saunders, M., Lewis, P., \& Thornhill, a. A. (2009). Research Methods for Business Students (5 ed.). Pearson.

[19] Smith, A., Chamberlain, D., Smit, H., Ncube, S., \& Chelwa, G. (December 2010). Kenya microinsurance landscape. The Centre for Financial Regulation and Inclusion.

[20] Teachers Service Commission. (2013). Schools Directory. Retrieved 05 21, 2014, from Teachers Service CommissionOnline Services: http://www.teachersonline.go.ke/masterbasic.aspx

[21] Trochim, W., \& Donnelly, J. P. (2006). The Research Methods Knowledge Base (Third ed.). Norwick: Atomic Dog Pub Inc. 